\title{
IMPACTS OF PHYTOESTROGENS ON LIVESTOCK PRODUCTION: REVIEW
}

\author{
N.M. Hashem and Y.A. Soltan \\ Department of Animal Production, Faculty of Agriculture, Alexandria University, Alexandria 21545, \\ Egypt
}

\section{SUMMARY}

(Received 10/2/2016, accepted 29/3/2016)

$\mathrm{P}$

hytoestrogens, polyphenolic compounds, are one of the major plant secondary metabolites found abundantly in animal diets. However, these phytochemicals play initial important roles in plant growth, development and maintenance. They also have many biological roles in animal body, affecting their productivity. The richest sources of phytoestrogens in animal diets are legumes, particularly, soybeans and clover. These plants often comprise substantial part of animal feed, thus presenting a potential source of phytoestrogens. The interest in these compounds was started earlier, over 50 years ago, when they have been known to affect fertility of an Australian sheep herd, resulting in an economic loss. The putative effects of phytoestrogens are based on their structural similarity to the mammalian estrogen $17 \beta$-estradiol $\left(\mathrm{E}_{2}\right)$ and thus their potency to bind with mammalian estrogen receptors. More attention has been paid to these metabolites since they can act as estrogen agonists or antagonists which make their effects are not expected.. The estrogenic activity of phytoestrogens depends on many factors such as chemical structure of the compound, bioavailability, animal specie, responsive tissue and its estrogen receptor (ER) sub-type $\left(E_{\alpha}\right.$ or $\left.E_{\beta}\right)$ and metabolites resulting from their fermentation and digestion. Reports showed that phytoestrogens could affect animal fertility and growth, quality of animal products and human health. This review illustrates the impacts of phytoestrogens on the livestock production system, focusing on physiology of reproduction, as well as the knowledge obtained from research in laboratory and field scales.

Keywords: Phytoestrogens, estrogenic activity, reproduction, farm animals

\section{INTRODUCTION}

Phytoestrogens are one of many secondary metabolites producing by plants during photosynthesis, they primarily involve in host-microbe interactions, defense mechanism (Graham, 1999). Chemically, phytoestrogens include more than 100 molecules those are belonging to different chemical classes such as isoflavones, flavones, coumestans, stilbenes, and lignans (Wocławek-Potocka et al., 2013). Effects of phytoestrogens on livestock production have been detected earlier. In the 1940s, it was noticed for the first time that red clover (a plant which is rich in the phytoestrogen coumestrol) pastures had negative effects on the fertility and fecundity of grazing sheep due to its hyperestrogenic activity, which is socalled clover disease (Braden et al. 1967; Yildiz, 2005). About 20 years later, similar observation has been noted in cows that had fertility disturbances resulting from periods of feeding with red clover (Kallela et al., 1984). Since this time interests with phytoestrogens have been increased especially when their effects on human and animal health and reproduction were found to be inconsistent. In farm animals, consumption of phytoestrogen rich-diets disturb hormonal balance in animal body leading to silent heat (Zduńczyk et al., 2005), progesterone deficiency (Piotrowska et al., 2006), embryonic loss (WocławekPotocka et al., 2005) and low semen quality (Glover and Assinder, 2006). On the other hand, inclusion of phytoestrogenic plant in diets of growing animals showed beneficial effects by stimulating weight gain and increasing the growth rate (Trenkle and Borroughs, 1978). Additionally, in human, a high intake of dietary phytoestrogens is suggested to be associated with a reduced incidence of breast and prostate cancer, cardiovascular diseases and osteoporosis (Cornwell et al., 2004) in populations whose diet contains an abundance of soy products, when compared with typical Western diets. These actions may be due to the antiestrogenic effects of phytoestrogens in human (Adlercreutz et al., 1995) and/or their antioxidant activity (Siow and Mann, 2010). Previous information about the biological role of phytoestrogen in humans and animals makes them an interesting material for more research discovering their negative and positive effects in the mammals. 


\section{Flavonoids}

A.1. Isoflavones

A.2. Flavones

A.3.Coumestans

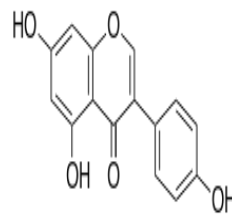

Genistein<smiles>O=c1c2c(O)cc(O)cc2oc2ccc(O)c(O)c12</smiles>

Quercetin

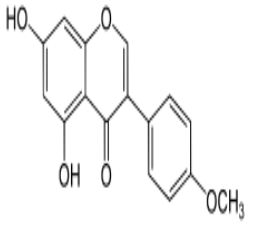

Biochanin A

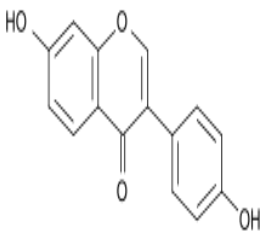

Daidzein

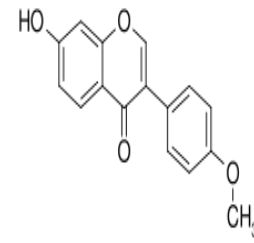

Formonontein
Kaempferol<smiles>O=c1oc2cc(O)ccc2c2c1oc1cc(O)ccc12</smiles>

Cumestrol

B.Non-flavonoids

(Lignans)

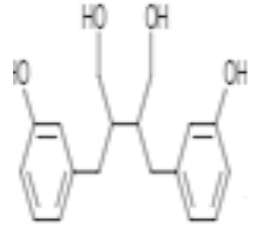

Enterodiol

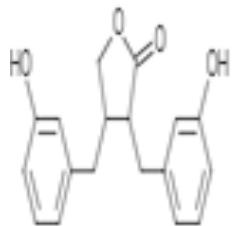

Enterolactone

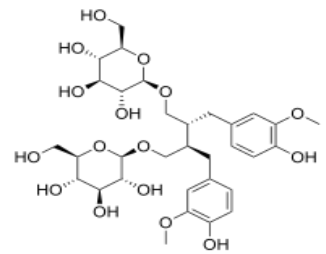

Secoisolariciresinol diglucoside

\section{Estilbenes}

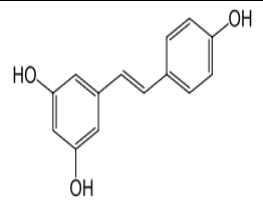

Resveratrol

D. Mycoestrogens
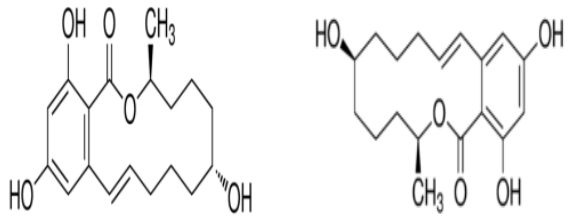

$\alpha$-Zearalenol

$\beta$-Zearalenol

Figure (1): Classification and chemical structure of different phytoestrogens.

\section{Chemical Structure of Phytoestrogens}

Phytoestrogens acquired their name as they have a chemical structure similar to that of mammalian estrogens which enables them to affect different mammalian estrogen responsive-tissues. Most of phytoestrogens are polyphenolic compounds belonging to two main groups: flavonoids and nonflavonoids known as lignans (such as secoisolariciresinol enterolactone and enterodiol). The majority of phytoestrogens belong to the flavonoid group which is divided to three sub-groups: 1) isoflavones (genistein, daidzein, glicetin, formononetin, biochanin A); 2) flavones (quercetin and kaempferol); 3) coumestans as cumestrol (Strauss et al., 1998). Additionally, there is also estilbenes (resveratrol) which is present in plants or in their seeds; also, some fungi can synthesize mycoestrogens zearalenone and its metabolites $\alpha$ and $\beta$-zearalenol (Moutsatsou, 2007). Naturally, most of phytoestrogens are conjugated with carbohydrate derivatives as glucose, this form is known as glycoside phytoestrogen. This conjugated form of phytoestrogens is biologically inactive when consumed. Therefore, the bioavailability of these 
compounds is controlled by the activity and by the type of both internal gastrointestinal and gut microflora enzymes in each animal specie (Patisaul and Jefferson, 2010).

\section{Binding Affinity of Phytoestrogens to Mammalian Estrogen Receptors}

In mammals, there are two sub-types of estrogen receptors (ERs) known as ER $\alpha$ and ER $\beta . \quad$ ER $\alpha$ is expressed predominantly in endometrium, breast cancer cells, ovarian stroma cells, efferent duct epithelium, and the hypothalamus, whereas ER $\beta$ is expressed in kidney, brain, bone, heart, lungs, intestinal mucosa, prostate, and endothelial cells. Phytoestrogens exert their effects primarily through binding to the estrogen receptor (ER) sub-types $\alpha$ or $\beta$ (ER $\alpha$ or ER $\beta)$. Phytoestrogens have lower affinity for ERs than estradiol $\left(E_{2}\right)$, and most of them exhibit a higher affinity for ER $\beta$ than for ER $\alpha$ by approximately 30 fold (Whitten and Naftolin, 1998; Pettersson and Gustafsson, 2001; Turner et al., 2007). Generally, the affinity of different phytoestrogens to the $E_{2}$ sub-types was studied using receptor binding affinity test. The ranking of the estrogenic potency of phytoestrogens for both ER sub-types in the transactivation assay is different; that is, $\mathrm{E}_{2}>$ zearalenone $=$ coumestrol $>$ genistein $>$ daidzein $>$ apigenin = phloretin $>$ biochanin $\mathrm{A}=$ kaempferol = naringenin $>$ formononetin = ipriflavone = quercetin = chrysin for $\mathrm{ER} \alpha$ and $\mathrm{E} 2>$ genistein $=$ coumestrol $>$ zearalenone $>$ daidzein $>$ biochanin $\mathrm{A}=$ apigenin $=$ kaempferol $=$ naringenin $>$ phloretin $=$ quercetin $=$ ipriflavone $=$ formononetin $=$ chrysin for ER $\beta$ (Kuiper et al., 1998).

The affinity of different phytoestrogens to ERs depends on many chemical structure elements including the presence of a phenolic ring that is indispensable for binding to estrogen receptor, low molecular weight near to that of estrogens $(\mathrm{MW}=272)$, distance between two hydroxyl groups at the isoflavones nucleus similar to that occurring in estradiol and optimal hydroxylation pattern (Yildiz, 2005). For example, genistein (4,5,7-trihydroxyisoflavone) has a higher binding affinity for the ERs than daidzein (4,7-dihydroxyisoflavone), the differential potency between genistein and daidzein could be ascribed to the presence of the 5-hydroxyl group of genistein which provides more identical chemical similarity to mammalian $\mathrm{E}_{2}$ (Bickoff, 1961; Shutt and Cox, 1972). Also the binding affinity of phytoetrogens could be attenuated by methylation of hydroxyl groups of isoflavones, instantly, the methoxy derivative of daidzein or formononetin has less estrogenic activity compared to daidzein (Bickoff, 1961). According to the previous facts, phytoestrogens are known to have a weak estrogenicity compared with endogenous estradiol $\left(\mathrm{E}_{2}\right)$. This is due to the lower affinity of phytoestrogens for ERs and the higher concentrations of isoflavones required to induce transcriptional activity of $\mathrm{E}_{2}\left(10^{4}\right.$ fold than $\mathrm{E}_{2}$ ). However, there are other aspects controlling their effects in vivo. Free circulating phytoestrogens is more than $50 \%$ versus $4 \%$ for $\mathrm{E}_{2}$, also the magnitude of concentration of phytoestrogen is one order higher than $\mathrm{E}_{2}(\mathrm{ng} / \mathrm{ml}$ versus $\mathrm{pg} / \mathrm{ml})$ (Retana-Márquez et al., 2012). This greater bioavailability to ERs may explain why phytoestrogens have in vivo potential effects. Interestingly, the transcriptional activity of phytoestrogens is not the only mechanism by which they disturb hormonal balance, but also they have non-genomic effects by modulating the concentration of endogenous estrogens by binding or inactivating some enzymes related to estrogen biosynthesis, such as $\mathrm{P} 450$ aromatase, 5 $\alpha$-reductase, 17 $\beta$ hydroxyesteroid dehydrogenase (17 $\beta-\mathrm{OHDH})$, topoisomerases, and tyrosine kinases (Watson et al., 2007; de Souza et al., 2010)

\section{Metabolism of Phytoestrogens in Ruminants}

Dietary consumed phytoestrogens are exposed to many chemical reactions in the elementary tract. Hydrolysis of the conjugation between phytoestrogen and its carbohydrate moiety producing aglycone phytoestrogen (biologically active form) is the most important chemical reaction (Fig. 2). This process takes place in rumen and/or intestine by the action of the $\beta$-glycosidase enzymes producing by gut microorganisms or intestinal epithelial glands, additionally it could be induced by the gastric hydrochloric acid (Lindsay and Kelly, 1970). However, re-conjugation of free phytoestrogens could be occurred in the epithelial cells of the gastrointestinal tract during the absorption. Following absorption, most of the free circulating phytoestrogens are re-conjugated mainly to glucuronic acid and to a lesser degree to sulphuric acid (Lundh, 1995; Branca and Lorenzetti, 2005). Also, they undergo further chemical reactions including demethylation, methylation, hydroxylation, chlorination, iodination, and nitration. In ruminants, phytoestrogens, mainly isoflavones, are bio-converted by the action of ruminal microflora to other metabolites. Both biochanin A and genistein are transformed to the p-ethyl phenol, whereas formonontin and daidzein are transformed to more potent estrogenic compound equol (Fig. 3; Benassayag et al., 2002; D'Alessandro et al., 2005).

\section{Sources of Phytoestrogens in Animal Feed Stuffs}

There are reports indicating that most of the legumes commonly used for feeding livestock contain from 5 to $25 \%$ phytoestrogens. The concentrations of phytoestrogens in plants vary depending on many environmental factors, such as: temperature, humidity, light, age of the plant, amount of fertilizer, and pathogens (Adams, 1995). The plant family most abundant in phytoestrogens is Leguminosae. Isoflavones as daidzein, genistein and glycetin are the predominant in soybeans. Biochanin A and 
formonontin are isolated from clover. Lignans are the main phytoestrogens in the flaxseeds, while coumestans are found in germs; for example beans sprouts and also in fodder crops (Price and Fenwick, 1985).

A

B

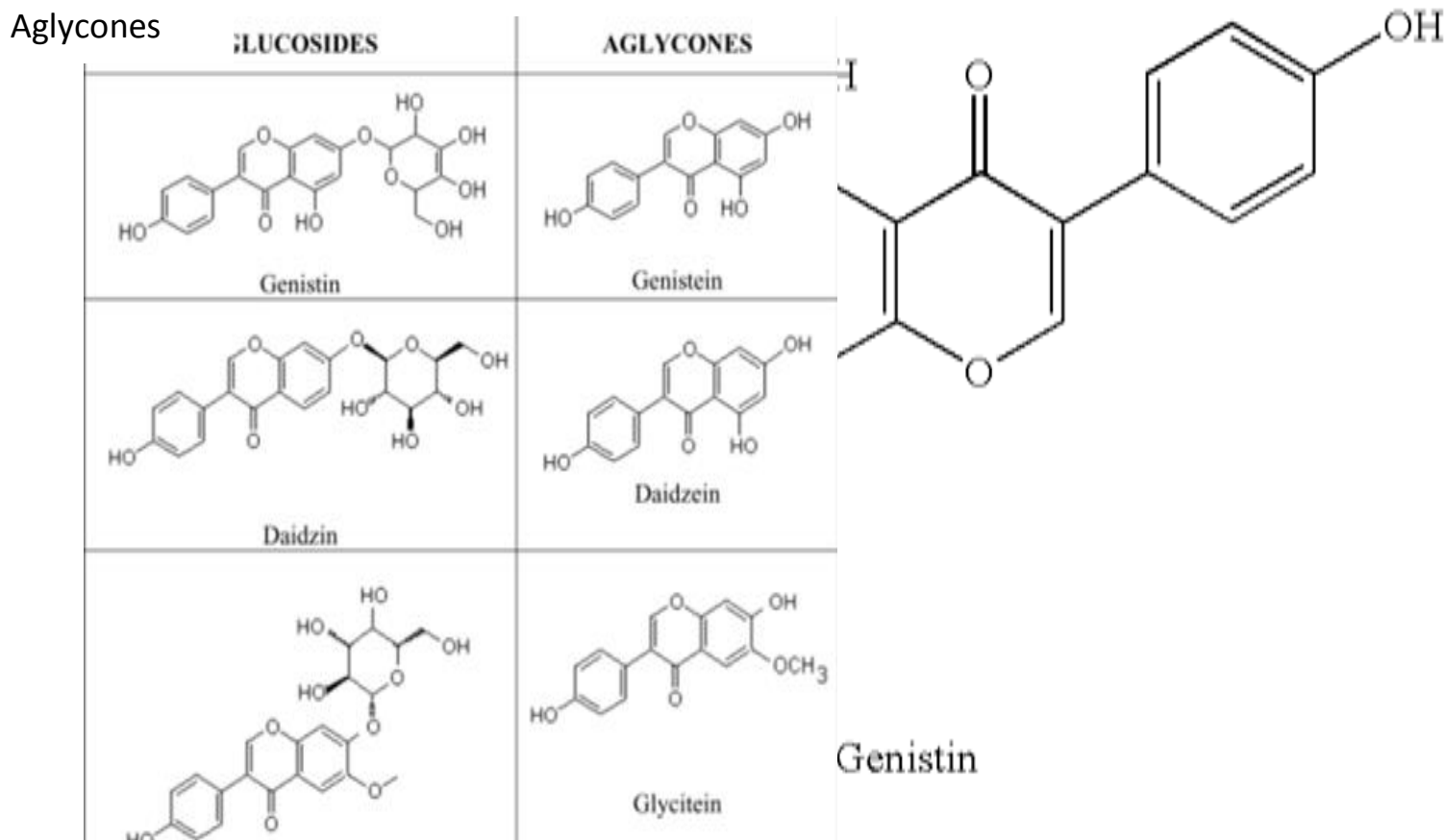

Glycitin

$\downarrow \begin{gathered}\text { hydrolyzing } \beta \text {-gly cosydic } \\ \text { linkange }\end{gathered}$

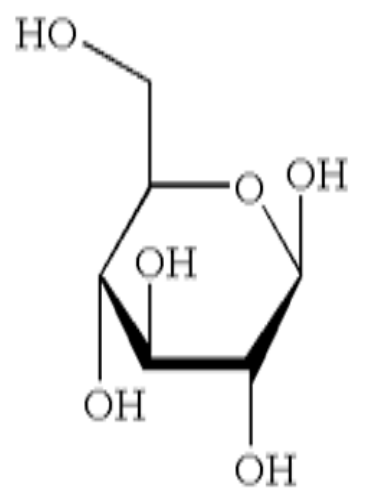

Glucose<smiles>O=c1c(-c2ccc(O)cc2)coc2cc(O)cc(O)c12</smiles>

Genistein

Figure (2): Conjugated and free forms of different phytoestrogens (A) and transformation of genistin (B) from glycoside form (a, biologically inactive) into aglycone form (b, biologically active) by the hydrolysis action of $\beta$-glycosidase enzyme. 


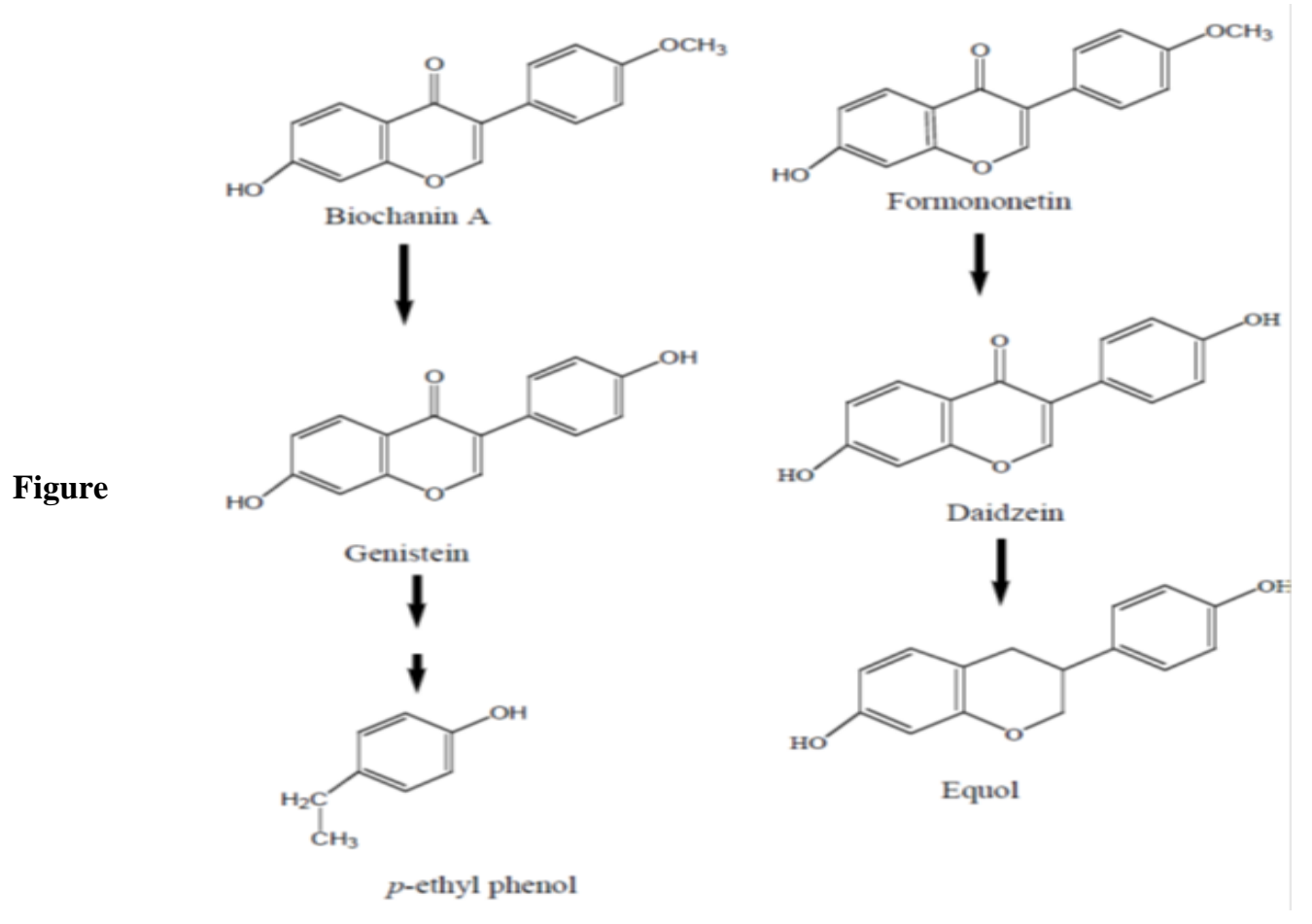

(3):

Metabolism of some isoflavones in ruminants.

\section{Impacts on Animal Productivity: \\ Reproduction in Females}

Because endogenous estrogen receptors are widely distributed in the entire reproductive axis (hypothalamus, pituitary, ovary and reproductive tract), it is expected that phytoestrogens can alter reproduction of females on different levels. Many studies have reported that phytoestrogens in legumes may act as antagonists or agonists of endogenous estrogen (Usui et al., 2002). Phytoestrogens generally inhibit endogenous estrogens production, leading to disturbances in the follicular development and lack of the occurrence of estrus (Rosselli et al., 2000). Further, it has been suggested that phytoestrogen compounds may disturb estrus and ovulation through their effects on the central nervous system (Wocławek-Potocka et al., 2005). So for example genistein, an isoflavone phytoestrogen, can stimulate the expression of immunoreactive ER $\alpha$ in the pituitary LH-cells, but not in the FSH-cells, and changes the endocrine activity of LH-producing cells of anestral ewes (Polkowska et al., 2004). In this context, a correlation was detected between blood plasma concentration of isoflavones and the incidence of silent heat in cows, where, Zduńczyk et al. (2005) compared between three herds of cows those had different levels of blood plasma of total isoflavones. It was found that the highest concentration of blood plasma total isoflavones $(4.9 \pm 0.5 \mu \mathrm{mol} / \mathrm{l}$ vs. $2.6 \pm 0.9 \mu \mathrm{mol} / 1$ and $1.0 \pm 0.3 \mu \mathrm{mol} / \mathrm{l})$ was detected in the herd with the highest incidence of silent heat ( $40.9 \%$ vs. 35.0\% and 7.0\%). In ewes, Hashem and Sallam (2012) suggested that feeding Egyptian clover to seasonal anestrus ewes around period of mating and early pregnancy might implicate with other environmental factors leading to an increase in silent heat and decrease in conception rate following estrous synchronization.

In heifers, higher concentrations of active metabolites of phytoestrogens in the corpus luteum (CL) tissues collected from heifers receiving soy diet have been detected compared to animals fed with standard fodder. These high concentrations of phytoestrogen metabolites were associated with lower concentrations of $\mathrm{P}_{4}$, leading to higher early pregnancy losses. Phytoestrogens and its metabolites could also affect establishment of pregnancy during early stages by increasing $\mathrm{PGF}_{2 \alpha} / \mathrm{PGE}_{2}$ ratio (Piotrowska et al., 2006). During early pregnancy, an increased concentration of PGE, and thus lower $\mathrm{PGF}_{2 \alpha} / \mathrm{PGE}_{2}$ ratio, is required which helps in blood vessels relaxation and improves blood flow to the uterus, preparing it for proper embryo implantation (Okuda et al., 2002). More recent study by Cools et al. (2014) showed that dairy cows fed soybean meal throughout three estrous cycles had reduced area occupied by steroidogenic and endothelial cells in the luteal biopsies compared to those fed rapeseed meal (low phytoestrogenic seeds). The reduction in the steroidogenic and endothelial cells in soybean fed cows was negatively correlated with blood concentrations of equol and glycitein. 
Interestingly, however, the estrogen-like effects of phytoestrogens and their metabolites during early pregnancy are not desirable. In non-pregnant cows, these effects may help in resumption of cyclicity and ovulation in post-partum cows (Wocławek-Potocka et al., 2005). During luteolysis, stimulation of $\mathrm{PGF}_{2 \alpha}$ secretion by estrogen-like substances accelerates the positive feedback loop between $\mathrm{PGF}_{2 \alpha}$ and other regulators of luteolysis, such as, for example, oxytocin (Goff, 2004) or TNF $\alpha$ (Skar zy'nski et al., 2009), leading to the pulsatile $\mathrm{PGF}_{2 \alpha}$ output from the endometrium during luteolysis in ruminants (McCracken et al., 1999).

\section{Reproduction in Males}

The effects of phytoestrogens on male fertility has increased in recent years as it has been demonstrated that estrogens play an important role in the male reproductive system (Rochira et al., 2005). Although there are only few reports, it has been shown that phytoestrogens also cause reproductive disruption in males. Some phytoestrogens exert an inhibitory effect on steroidogenic enzymes (Strauss et $a l .$, 1998). For example, isoflavonoids and lignans inhibit $5 \alpha$-reductase activity, thereby reducing the conversion of testosterone to the active form DHT (Evans et al., 1995). A high phytoestrogen diet in male rats can also block spermatogenesis, induce germ cell apoptosis (Assinder et al., 2007), and decrease the expression of ER $\alpha$ in the cauda epididymis as well as increase lipo-peroxidation in epididymal sperm. These effects are possibly mediated by disruption of the steroid regulation of the epididymis, resulting in decreased quality of sperm, and thereby reducing fecundity (Glover and Assinder, 2006). On the other hand, chronic dietary exposure to genistein in combination with vinclozoline (a fungicide considered an endocrine disruptor) reduces sperm count and motility, litter size and increased post-implantation loss (Eustache et al., 2009). In cryopreserved bull spermatozoa, genistein can affect a protein tyrosine phosphorylation-independent signal transduction pathway that is involved in sperm capacitation, the acrosome reaction and sperm- pellucid zone binding, thereby decreasing 40-50\% the acrosome reaction (Menzel et al., 2007). Besides, mouse and human spermatozoa exposed in vitro to different levels of genistein and daidzein , alone or in combination, accelerate capacitation (Adeoya-Osiguwa et al., 2003) and acrosome loss, which may possibly impair fertility (Fraser et al., 2006).In bovines, ingestion of fodder with high quantities of coumestrol causes glandular metaplasia in both prostate and bulbourethral glands (Lenis et al., 2010), gynecomastia and even galactorrhea (Romero et al., 1997).

\section{Animal Growth}

It is interesting to know that there are evidences on beneficial anabolic actions of the phytoestrogenic plants observed in the growing animals, but not unequivocally established. Phytoestrogens showed beneficial effects when fed to monogastric or ruminant animals, stimulating weight gains and increasing the growth rate (Trenkle and Borroughs, 1978). Previous works indicated that growing rabbits fed on commercial diets supplemented with $0.1 \mathrm{~g} / \mathrm{kg}$ of a subterranean clover extract compared to a group supplemented with $1 \mathrm{mg} / \mathrm{kg}$ of clenbuterol (b-agonist) showed very close average daily gain values and meat percentages (Pace et al., 1994). Also, Moorby et al. (2004) found that red clover-fed lambs had a significantly higher live weight gain than grass-fed lambs with no substantial differences on carcass quality. This enhancement was associated with higher concentrations of growth hormone and insulin like growth factor-1 in red clover-fed lambs compared to grass-fed lambs. Same results were obtained by Pace et al. (2006) who reported that male and female lambs fed subterranean clover selected for low formononetin content had a significant higher body weight gain compared with those fed Italian ryegrass (non-estrogenic roughage).

\section{CONCLUSION}

Despite the abundant researches that carried out discussing the biological roles of phytoestrogens in humans and farm animal, the paradox effects of phytoestrogens still present a good material for further studies. Specially, the effects of these compounds depend on multifactor such the chemical form of the phytoestrogen, the route of administration, the metabolism, the physiological status, the age, and the time and the level of exposure. Additionally, the researches on the effects of other phytoestrogens rather than soybean isoflavones desire more considerable evaluation in humans and animals.

\section{REFERENCES}

Adams, N.R. 1995. Detection of the effects of phytoestrogens on sheep and cattle. Journal of Animal Science, 73: 1509-1515.

Adeoya-Osiguwa, S.A., S. Markoulaki, V., Pocock, S.R. Milligan and L.R. Fraser, 2003. 17ß-Estradiol and environmental estrogens significantly affect mammalian sperm function. Human Reproduction, 18:100-107. 
Adlercreutz, C.H., B. R. Goldin and S. L. Gorbach, K.A. Höckerstedt, S. Watanabe ;E.K. Hämäläinen, M.H. Markkanen, T.H. Mäkelä, K.T., T. Adlercreutz, 1995. Soybean phytoestrogen intake and cancer risk. The Journal of Nutrition, 125: 757-770.

Assinder S., R. Davis , M. Fenwick and A. Glover, 2007. Adult-only exposure of male rats to a diet of high phytoestrogen content increases apoptosis of meiotic and post-meiotic germ cells. Reproduction, 133: $11-19$.

Benassayag M., A. Perrot and F. Ferre, 2002. Phytoestrogens as modulators of steroid action in target cells. Journal of Chromatography B, 777: 233-248.

Bickoff, E.M., 1961. Estrogen-like substances in plants. In 22nd Biology Colloquium, Physiology of Reproduction, pp 93-118, Oregon State University 1961.

Braden A.W.H., N.K. Hart and J.A. Lamberton, 1967. The oestrogenic activity of and metabolism of certain isoflavones in sheep. Australian Journal of Agricultural Research, 18: 335-348.

Branca, F and S. Lorenzetti, 2005. Health effects of phytoestrogens. Forum Nutrition, 57:100-111.

Cools, W., V. Broeckb, L. Vanhaeckec, A. Heyerickd, P. Bossaerte, M. Hostensa and G. Opsomer, 2014. Feeding soybean meal increases the blood level of isoflavones and reduces the steroidogenic capacity in bovine corpora lutea, without affecting peripheral progesterone concentrations. Animal Reproduction Science 144: 79-89.

Cornwell, T., W. Cohick and I. Raskin, 2004. Dietary phytoestrogens and health. Phytochemistry, 58: $37-43$.

D'Alessandro, T.L., B.J. Boersma-Maland, T.G. Peterson, J. Sfakianos , J.K. Prasain R.P. Patel , V.M. Darley-Usmar, N.P. Botting, S. Barnes, 2005. Metabolism of phytoestrogen conjugates. Methods of Enzymology, 400:316-42.

de Souza, P.L., P. J. Russell, J. H. Kearsley and L.G. Howes, 2010. Clinical pharmacology of isoflavones and its relevance for potential prevention of prostate cancer. Nutrition Reviews, 68: 542-555.

Eustache, F., F. Mondon, M.C. Canivenc-Lavier, C. Lesaffre, Y. Fulla,R. Berges J.P.Cravedi, D. Vaiman and J. Auger, 2009. Chronic dietary exposure to a low-dose mixture of genistein and vinclozolin modifies the reproductive axis, testis transcriptome, and fertility. Environmental Health Perspectives, 117:1272-1279.

Evans, B.A., K. Griffiths and M.S. Morton, 1995. Inhibition of 5 alpha-reductase in genital skin fibroblasts and prostate tissue by dietarylignans and isoflavonoids. Journal of Endocrinology. 147:295-302.

Fraser, L.R., E. Beyret, S.R. Milligan and S.A. Adeoya-Osiguwa, 2006. Effects of estrogenic xenobiotics on human and mouse spermatozoa. Human Reproduction, 21:1184-1193.

Glover, A. and Assinder, S.J. 2006. Acute exposure of adult male rats to dietary phytoestrogens reduces fecundity and alters epididymal steroid hormone receptor expression. Journal of Endocrinology.189: $565-573$.

Goff, A.K., 2004. Steroid hormone modulation of prostaglandin secretion in the ruminant endometrium during the estrous cycle. Biology of Reproduction, 71: 11-16.

Graham ,T., 1999. Biosynthesis and distribution of phytoestrogens and their roles in plant defense, signal transduction, and cell-to-cell signaling. Journal of Medicinal Food, 2: 93-97.

Hashem, N.M. and S. Sallam, 2012. Sexual and ovarian activity of crossbred ewes fed different types of roughage during seasonal anestrus. Small Ruminant Research107, 136-140.

Kallela, K., K. Heinonen and H. Saloniemi, 1984. Plant oestrogens; the cause of decreased fertility in cows. A case report. Nordisk Veterinaermedicin, 36: 124-129.

Kuiper, G.J.M., G.J. Lemmen, B. Carlsson, J.C. Corton, S.H. Safe, P.T. Saag, B. Burg an d J.Gustafsson, 1998. Interaction of estrogenic chemicals and phytoestrogens with estrogen receptor $\beta$. Endocrinology, 139:4252-4263.

Lenis, Y.Y., M.T. Gutiérrez and A.M. Tarazona, 2010. Efectos de los fitoestrógenos en la reproducción animal. Revista Facultad Nacional de Agronomía, Medellín. 63:5555-5565.

Lindsay, D.R. and R.W. Kelly, 1970. The metabolism of phytooestrogens in sheep. Australian Veterinary Journal. 46: 219-222.

Lundh, T.J.O., 1995. Metabolism of estrogenic phytoestrogens in domestic animals. Proceedings of the Society for Experimental Biology and Medicine, 208:33-39.

McCracken, J.A., E. E. Custer and J. C. Lamsa, 1999. Luteolysis: a neuroendocrine-mediated event. Physiological Reviews, 79: 263-323.

Menzel, V.A., E. Hinsch, W. Hägele and K.D. Hinsch, 2007. Effect of genistein on acrosome reaction and zona pellucid binding independent of protein tyrosine kinase inhibition in bull. Asian Journal of Andrology, 9:65-658. 
Moorby, J. M., M.D. Fraser, V.J. Theobald, J.D. Wood and W. Haresign, 2004. The effect of red clover formononetin content on live-weight gain, carcass characteristics and muscle equal content of finishing lambs. Animal Science, 79: 303-313.

Moutsatsou, P., 2007. The spectrum of phytoestrogens in nature: our knowledge is expanding. Hormones, 6:173-193.

Okuda, K., D. J. Skar zy'nski, and Y. Miyamoto, 2002. Regulation of endometrial prostaglandin F2 $\alpha$ synthesis during luteolysis and early pregnancy in cattle," Domestic Animal Endocrinology, 23: 255264.

Pace, V., K. Carbone, F. Spirito, M. Iacurto, M.G. Terzano, M. Verna, F. Vincenti and D. Settineri, 2006. The effects of subterranean clover phytoestrogens on sheep growth, reproduction and carcass characteristics. Meat Science 74: 616-622.

Pace, V., D. Settineri, G. Masoero and G. Bergoglio, 1994. Comparison between the effects of b-agonists and phytoestrogens on the performances of growing rabbits. In Proceedings of the 45th Annual Meeting of the European Association for Animal Production (N5, 63, p. 180), 5-8 September 1994, Edinburg, Scotland.

Patisaul, H.B. and W. Jefferson, 2010. The pros and cons of phytoestrogens. Frontiers in Neuroendocrinology, 31:400-419.

Pettersson, K. and J.A., Gustafsson, (2001). Role of estrogen receptor beta in estrogen action. Annual Review of Physiology, 63:165-192

Piotrowska, K.K., I. Wocławek-Potocka and M. M. Bah et al., 2006. Phytoestrogens and their metabolites inhibit the sensitivity of the bovine corpus luteum to luteotropic factors. Journal of Reproduction and Development, 52: 33-41.

Polkowska, J., Y. Riddersträle, M. Wan’kowska, K, Romanowicz, T. Misztal and A. Madej, (2004). Effects of intracerebroventricular infusion of genistein on gonadotrophin subunit mRNA and immunoreactivity of gonadotrophins and oestrogen receptor- $\alpha$ in the pituitary cells of the anoestrous ewes. Journal of Chemical Neuroanatomy, 28: 217-224.

Price, K.R. and G.R. Fenwick, 1985. Naturally occurring oestrogens in foods - a review. Food Additives and Contaminants, 2:73-106.

Retana-Márquez , S., H. Hernández, J.A. Flores, M. Muñoz-Gutiérrez, G. Duarte , J. Vielma, G. FitzRodríguez, I. G. Fernández, M. Keller and J. A. Delgadillo, 2012. Effects of phytoestrogens on mammalian reproductive physiology. Tropical and Subtropical Agroecosystems, $15129-145$.

Rochira, V., A.R. Granata, B. Madeo, L, Zirilli, G.Rossi, G.and C. Carani, 2005. Estrogens in males: what have we learned in the last 10 years? Asian Journal of Andrology, 7: 3-20.

Romero-R, C.M., M.R. Tarragó Castellanos, R. Muñoz Mendoza, R. Arista Reyes and A. Rosado García, 1997. Síndrome estrogénico en vacas lecheras por consumo de alfalfas con grandes cantidades de coumestrol. Veterinaria México, 28:25-30.

Rosselli, M.K., Reinhard,B. Imthurn, P.J. Keller and R.K. Dubey, 2000. Cellular and biochemical mechanisms by which environmental estrogens influence reproductive function. Human Reproduction, 6:332-350.

Shutt, D.A. and R.I.Cox, 1972. Steroid and phytoestrogen binding to sheep uterine receptors in vitro. Journal of Endocrinology, 52: 299-310.

Siow, R. C. M. and G. E.Mann, 2010. Dietary isoflavones and vascular protection: activation of cellular antioxidant defenses by SERMs or hormesis?. Molecular Aspects of Medicine, 31: 468-477.

Skar zy'nski, D., K. Piotrowska and M. Bah et al., 2009. Effects of exogenous tumour necrosis factor- $\alpha$ on the secretory function of the bovine reproductive tract depend on tumour necrosis factor- $\alpha$ concentrations. Reproduction in Domestic Animals, 44: 371-379.

Strauss, L., R. Santti, N. Saarinen, T. Streng, S. Joshi and S. Makela, 1998. Dietary phytoestrogens and their role in hormonally dependent disease. Toxicology Letters, 102-103:349-354.

Trenkle, A. and W. Borroughs, 1978. Physiological effects of estrogens in animal feeds with emphasis on growth of ruminants. Nutrition and drug interrelations. New York: Academic Press, pp. 577-611.

Turner, J.V., S. Agatonovic-Kustrin and B.D.Glass, 2007. Molecular aspects of phytoestrogen selective binding at estrogen receptors. Journal of Pharmaceutical Sciences, 96: 1879-1885.

Usui, T., Y. Ikeda, T. Tagami, K. Matsuda, K. Moriyama, K. Yamada, H. Kuzuya, S. Kohno and A. Shimatsu, 2002. The phytochemical lindleyin, isolated from Rhei rhizoma, mediates hormonal effects through estrogen receptors. Journal of Endocrinology, 175: 289-296.

Watson, C.S., R. A. Alyea, Y. J. Jeng and M. Y. Kochukov, 2007. Nongenomic actions of low concentration estrogens and xenoestrogens onmultiple tissues. Molecular and Cellular Endocrinology, 27:1-7.

Whitten, P.L. and F. Naftolin,1998. Reproductive actions of phytoestrogens. Baillieres Clinical Endocrinology and Metabolism, 12:667-690. 
Wocławek-Potocka I., C. Mannelli, D. Boruszewska, I. K. Zieba,T. WaVniewski and D. J. SkarHyNski, 2013. Diverse effects of phytoestrogens on the reproductive performance: Cow as a model. International Journal of Endocrinology, 2013:1-15.

Wocławek-Potocka, I., M.M. Bah and A. Korzekwa et al., 2005. Soybean derived phytoestrogens regulate prostaglandin secretion in endometrium during cattle estrous cycle and early pregnancy. Experimental Biology and Medicine, 230: 189-199.

Yildiz, F., 2005. Phytoestrogens in Functional Foods. Taylor \& Francis. Ltd. Pp. 3-5: 210-211.

Zduńczyk, S., M. Piskuła, T. Janowski, W. Barański and M. Raś, 2005. Concentrations of isoflavones in blood plasma of dairy cows with different incidence of silent heat. Bulletin of the Veterinary Institute in Pulawy, 49:189-191.

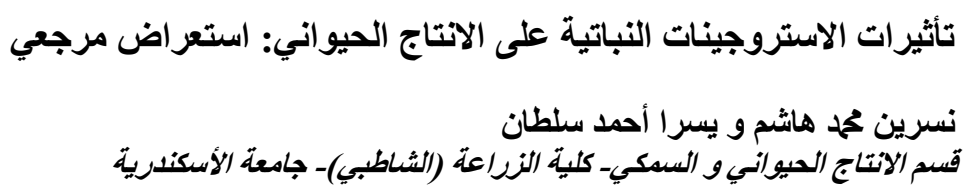

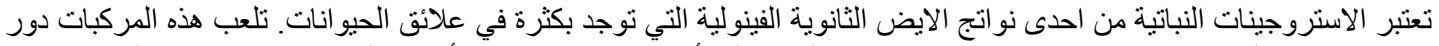

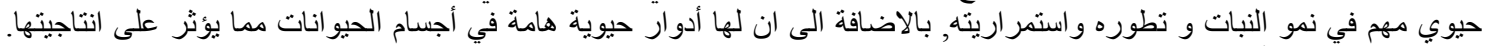

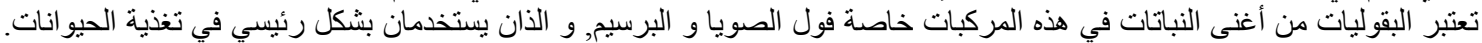

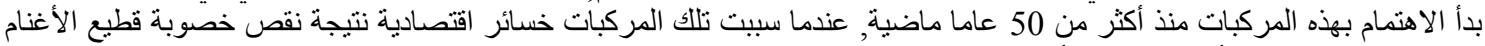

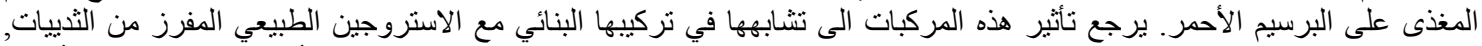

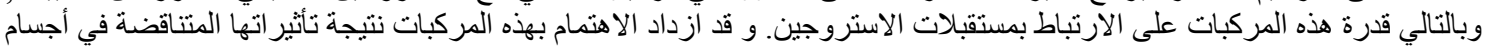

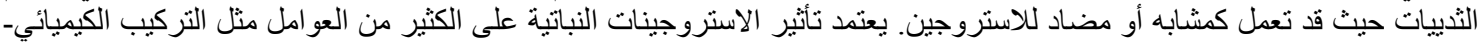

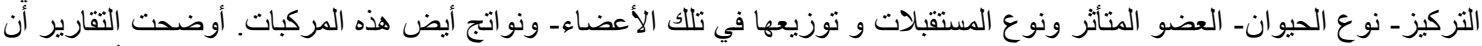

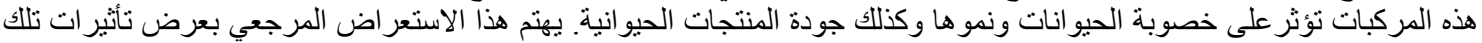

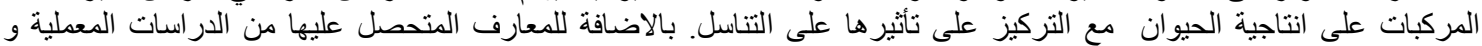

